\title{
Derkje Hazewinkel-Suringa: moed en middenweg
}

Leny de Groot-van Leeuwen

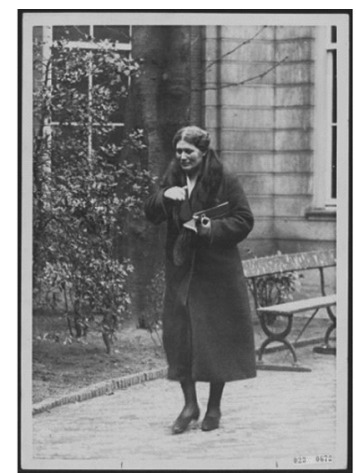

Derkje Hazewinkel-Suringa op de binnenplaats van de Oudemanhuispoort

\section{Inleiding}

Zoek in universiteitsbibliotheken naar juidische leer- en handboeken van weleer en je treft onder de auteurs op één uitzondering na louter mannen aan. ${ }^{1}$ Die uitzondering is Derkje Hazewinkel-Suringa (1889-1970). Haar Inleiding tot de studie van het Nederlands strafrecht uit 1953 vormde voor generaties van juristen de basis van hun kennis op het gebied van het strafrecht en het strafprocesrecht. De veronderstelling dat zij een belangrijke factor is geweest voor het Nederlandse rechtssysteem onderzoek ik in deze bijdrage. ${ }^{2}$ Heeft Hazewinkel-Suringa bijgedragen aan de verbreiding en vernieuwing van rechtsregels en rechtsnormen? Welke rol speelde zij in de juristerij? Was zij een factor van belang in deze of andere opzichten? Deze vragen worden beantwoord op basis van primaire en secundaire bronnen, zoals biografische studies, rechtshistorische literatuur en het recent gedigitaliseerde archief van historische kranten van de Koninklijke Bibliotheek.

1 Zie de bekende boeken van Asser, Corstens, Melai, Molengraaff, Remmelink, Tak, Van Apeldoorn en Van Bemmelen.

2 Schuyt onderscheidt drie afzonderlijk elementen van het rechtssysteem: het geheel van regels, normen en beginselen (het ideële element), het geheel van organisaties en de daarin werkende ambtsdragers en het geheel van concrete beslissingen en handelingen van ambtsdragers en leden van de samenleving in het algemeen, althans voor zover die in verband kunnen worden gebracht met het ideële element (Schuyt 1981, p. 11-18). 
Leny de Groot-van Leeuwen

\section{Biografische achtergrond}

Derkje Hazewinkel-Suringa was de eerste vrouwelijke hoogleraar aan de Amsterdamse Universiteit en de eerste vrouwelijke hoogleraar aan een rechtenfaculteit in Nederland. Zij werd op 25 maart 1889 geboren in Groningen, waar ze opgroeide als enig kind. Haar vader was als ambtenaar werkzaam op de gemeentesecretarie. ${ }^{3} \mathrm{Na}$ de vijfde klas van het gymnasium deed zij staatsexamen in 1907. Vervolgens bezocht zij de huishoudschool ${ }^{4}$ en volgde aan de Groningse universiteit, zoals ze zelf schreef voor haar plezier, colleges psychologie en logica bij professor Gerard Heymans (1857-1930)..$^{5}$ Op 21-jarige leeftijd trouwde Derkje met Cornelis Hazewinkel, leraar geschiedenis en Nederlands en later conrector aan het Barlaeus-gymnasium te Amsterdam.

Hazewinkel-Suringa ging pas in 1921 studeren toen haar drie kinderen op de middelbare school zaten. Eenmaal op de universiteit stortte zij zich naast haar huishoudelijke taken op de rechtsgeleerdheid. Zij studeerde rechten aan de Amsterdamse Gemeentelijke Universiteit en slaagde cum laude zowel voor het kandidaatsexamen in 1922 als voor het doctoraalexamen in $1925 .{ }^{6} \mathrm{Na}$ haar kandidaatsexamen werkte zij als student-assistent bij de romanist Henri Hijmans, na haar doctoraal examen was zij vier jaar assistent bij Paul Scholten; in die hoedanigheid gaf zij onder andere college in het erfrecht. ${ }^{7}$ Op 19 juni 1931 promoveerde zij, eveneens cum laude, op een proefschrift over eigendomsoverdracht in het Romeins recht. ${ }^{8}$ Een jaar later werd zij benoemd tot hoogleraar aan dezelfde faculteit. De kindergeneeskundige Cornelia de Lange was haar als eerste vrouwelijke gewoon hoogleraar in Nederland in 1927 voorgegaan aan dezelfde universiteit. ${ }^{9}$ Tien jaar daarvoor was Johanna Westerdijk benoemd tot buitengewoon hoogleraar in de plantenziektekunde aan de Rijksuniversiteit Utrecht. ${ }^{10}$

Ambtenaressen werden in die tijd ontslagen zodra zij trouwden, maar het benoemingsbeleid aan de Gemeentelijke Amsterdamse universiteit was liberaler dan aan de Rijksuniversiteiten. ${ }^{11}$ Toch is de benoeming van Hazewinkel-Suringa niet zonder slag of stoot gegaan. De vacature straf- en strafprocesrecht was ontstaan door het overlijden van prof. Van Dijck. Daar zij geen ervaring had op het gebied van het strafrecht werd de benoeming van Hazewinkel-Suringa op deze leerstoel wel een kredietbenoeming genoemd. ${ }^{12}$

P.L. Nève, 'Suringa, Derkje (1889-1979)', in: Bibliografisch Woordenboek van Nederland.

Destijds volgden veel meisjes een zogeheten vormingsklas aan een huishoudschool nadat zij een mulo-, mms-, hbs- of gymnasiumdiploma behaald hadden ter voorbereiding op het huwelijk of ter overbrugging naar een vervolgstudie.

Hazewinkel-Suringa 1968, p. 68.

Bataviaasch nieuwsblad 11 januari 1926.

Enschedé 1970, p. 181-184.

Hazewinkel-Suringa 1931.

Knegtmans 2007, p. 338.

Noordenbos 1998, p. 78.

Knegtmans 2007.

De Sumatra post 2 januari 1932. 


\section{Rolmodel}

Over haar benoeming is, aldus een oud-student van haar, 'zoo onsympathiek veel te doen geweest. Men heeft zich soms niet kunnen onttrekken aan den indruk, dat een deel van het verzet tegen het professorraat van dr. Hazenwinkel-Suringa eenvoudig het reactionaire verzet was tegen het benoemen van een vrouw, en dan nog wel een gehuwde vrouw, moeder van drie kinderen, in een dergelijke hooge functie!'13

Kort na haar benoeming tot hoogleraar hield Hazewinkel-Suringa, de 'nieuwe ster aan den professoralen hemel' ${ }^{14}$ een voordracht over het strafrecht op de jaarvergadering van De Nederlandsche Vereeniging voor Vrouwenbelangen en Gelijk Staatsburgerschap. Uitgebreid wordt in De Gooi en Eemlander ingegaan op het thema vrouwen in de wetenschap. 'Niet alleen naar haar rede was een ieder benieuwd, maar ook - laten wij dit eerlijk toegeven - naar haar persoon. De mannelijke professor, hoe groot de roep ook mag zijn van zijn wetenschappelijk kennen, doet bij het publiek zelden eenige vragen rijzen, maar de vrouwelijke hooggeleerde doet dit wel. Het zal wel komen doordat man en wetenschap elkaar altijd hebben ingesloten, of juister gezegd dat zij elkaar altijd hebben kunnen insluiten, terwijl de vrouw eeuwen achtereen beoordeeld is naar de gaven van haar hart en slechts den laatsten tijd - en ook nog lang niet door allen - ook naar die van haar geest. Wie gemeend had dien avond een vrouwelijke professor te zien en te hooren, bij wie het vrouwelijke min of meer op en achtergrond was geraakt, zag zijn verwachting onverwezenlijkt. Voor ons stond ene vrouw, die we op het eerste gezicht een eenvoudige frissche huismoeder zouden noemen (hetgeen zij tevens ook is) en niets van haar voorkomen en wijze van optreden en spreken kon doen vermoeden dat haar intellect een zelfde hoogte had bereikt als eertijds alleen den man mogelijk was.'

Dit beeld van een echte vrouw en huismoeder doemt ook op uit een stukje van een voormalige student van de pas benoemde hoogleraar. Omdat HazewinkelSuringa, althans in die tijd, niet wilde dat er een foto van haar in de kranten zou verschijnen, vroeg hij zich af of zij zijn geschreven herinneringen wel op prijs zou stellen. Hij zocht haar als student eens op met een juridische vraag en verhaalde daarover in Het volk, dagblad voor de arbeiderspartij: 'Ik vond haar thuis druk bezig aan een jurk voor haar jongste dochter. Het blonde meiske was erbij en werkte op haar broddellapje plezierig mee.' ${ }^{15}$

De wijze waarop Derkje Hazewinkel-Suringa haar verschillende rollen van huisvrouw, moeder en hoogleraar combineerde past wonderwel in het gedachtegoed van de psycholoog Gerard Heymans, de hoogleraar bij wie zij voor haar huwelijk 'voor haar plezier' colleges volgde. Heymans had rechten en filosofie gestudeerd, maar werd de grondlegger van de psychologie in Nederland. In 1910 verscheen zijn Psychologie der vrouwen waarin hij uiteenzette dat vrouwen en mannen gelijkwaardig zijn, maar verschillen; dat laatste niet zozeer in capaciteiten als wel in

13 Het Volk, dagblad voor de arbeiderspartij 21 januari 1932.

14 De Gooi- en Eemlander 15 mei 1932.

15 Het Volk, dagblad voor de arbeiderspartij 21 januari 1932. 
Leny de Groot-van Leeuwen

aard en interesses. Vrouwen zijn emotioneler, meer empathisch en hebben meer belangstelling voor opvoeding, kunst en de praktische kanten van het leven, mannen zijn meer geïnteresseerd in abstract denken en wetenschap. Bij vrouwen overheerst de emotionele, bij mannen de intellectuele belangstelling, aldus Heymans. ${ }^{16}$

In de levensloop van Hazewinkel-Suringa zien wij veel kenmerken terug die gehuwde vrouwen tot en met de jaren zestig van de twintigste eeuw gemeenschappelijk hadden, zij het dat zij naast het huisvrouwenbestaan een wetenschappelijke werkkring had. Voor het overige gedroeg zij zich overeenkomstig het traditionele vrouwbeeld. Zij trouwde, was huismoeder, ging pas studeren nadat de kinderen wat ouder waren, verstelde kleren en bleef dit doen als een student langskwam met studievragen. Zij vestigde daar echter nooit de aandacht op; ze afficheerde zich niet als vrouw en bracht dit nergens publiek in stelling. Dat deden anderen, zoals de journalist van De Gooi- en Eemlander die gefascineerd en enigszins verbaasd kijkt naar de vrouw en moeder achter het katheder. Zo werd ze toch tot een baken voor gehuwde geleerde vrouwen. In Leiden is een straat naar Hazewinkel-Suringa genoemd ${ }^{17}$ en het opinieweekblad Elsevier plaatste haar op de elfde plaats van de lijst van vijftig vrouwen die in de twintigste eeuw een bijzondere rol hebben gespeeld in Nederland. ${ }^{18} \mathrm{Zij}$ heeft en had impact. Als rolmodel voor gehuwde vrouwen was zij een succes.

\section{Leerstoel en studenten}

Gedurende de jaren dertig van de vorige eeuw volgden in totaal ongeveer 10.000 studenten wetenschappelijk onderwijs in Nederland. Ongeveer elf procent daarvan was student in de rechtsgeleerdheid. ${ }^{19}$ In het studiejaar 1931-1932 studeerden 653 vrouwen, dat was bijna 27 procent van de studenten, aan de gemeentelijke universiteit van Amsterdam. ${ }^{20}$ Landelijk was het percentage vrouwelijke studenten tot in de jaren vijftig onder de twintig procent. ${ }^{21}$

Vanaf haar benoeming tot hoogleraar gaf Hazewinkel-Suringa colleges strafrecht voor de reguliere rechtenstudenten, maar ook gaf zij les aan de officieren van de land- en zeemacht en van de Koninklijke Marechaussee, die in Amsterdam voor militair jurist studeerden. Er werden alleen colleges gegeven, oefenrechtbanken werkgroepen of een strafrechtinstituut bestonden toen nog niet. 'Destijds (...) was er niets dan die ene zaal, waarin over de honderd studenten kwamen luiste-

Zie www.prof.burgwijk.nl/ straatnamen.

'Elseviers top-50 van vrouwen die de twintigste eeuw maakten', Elsevier 22 augustus 1998. Maar in het recent verschenen boek 1001 vrouwen uit de Nederlandse geschiedenis ontbreekt zij (Kloek 2013).

19 Zie Hagendijk 1980, De Roos 1981 en CBS 2011. Opgemerkt moet worden dat de cijfers enigszins uiteenlopen. Zo vermeldt De Roos elf procent rechtenstudenten zowel in 1930 als in 1937, maar komt Hagendijk op vijftien procent in 1930 en veertien procent in 1947.

20 Knegtmans 1998 en Knegtmans 2007, p. 336.

21 Bosch 1994. 
ren naar één hoogleraar. ${ }^{22}$ Studenten ontmoetten hun hooglaren echter niet alleen op college, maar, zoals wij lazen, soms ook thuis. Over de afgestudeerde juristen werden destijds inlichtingen verstrekt door de hoogleraren. HazewinkelSuringa schreef deze altijd met de hand. Een collega van haar merkte op dat zij daarin naast de bereikte studieresultaten ook altijd melding maakte van de persoon van degene die daarachter schuilging. ${ }^{23}$

Haar inaugurele rede ging over 'De straf en haar achtergrond'. Hierin keerde zij zich tegen de vergeldingsleer en koos voor een theorie waarin de bescherming van de rechtsorde als eerste strafdoel gezien wordt. ${ }^{24}$ Haar belangrijkste werk voltooide zij meer dan twintig jaar na haar benoeming als hoogleraar, in 1953: de Inleiding tot de studie van het Nederlands strafrecht. Dit boek kende lange tijd geen evenknie en werd vele malen herdrukt en bewerkt. Vlak voor haar overlijden in 1970 heeft Hazewinkel-Suringa de latere procureur-generaal bij de Hoge Raad, prof. J. Remmelink, gevraagd de bewerking van de inleiding op zich te nemen. ${ }^{25}$ Vanaf de vijfde druk in 1971 heeft hij dat inderdaad gedaan. ${ }^{26}$ In de vijftiende druk uit 1996 was haar naam als auteur verdwenen, maar opgenomen in de titel die nu luidde: Mr. D. Hazewinkel-Suringa's Inleiding tot de studie van het strafrecht. Het boek zou de basis vormen voor de strafrechtopleiding van vele rechtenstudenten.

De Inleiding werd direct na publicatie lovend besproken in het Nederlands Juristenblad. ${ }^{27}$ Niet alleen de inhoud maar ook de heldere, levendige stijl werd zeer geprezen. Hazewinkel-Suringa wil, aldus de recensent, vooral voor de studenten de inprenting bevorderen. Het boek is naar zijn mening duidelijk afkomstig van een enthousiaste hoogleraar die studenten wil leren om zelf te denken door te laten zien hoe er over strafrechtelijke vraagstukken wordt gedacht en door ze mee te nemen aan de hand van haar eigen gedachtegoed. Het is niet zozeer een naslagwerk voor praktijkjuristen als wel een werk voor studenten dat geschreven is in een heldere, levendige stijl. Deze kwalificaties keren in besprekingen van latere bewerkingen terug. ${ }^{28}$ Op belangrijke punten kiest Hazewinkel-Suringa geen partij of laat zij doorschemeren dat zij tegenover een bepaalde rechtskwestie sceptisch staat, zo schrijft Constantijn Kelk.

Jarenlang vervulde Hazewinkel-Suringa het professorale ambt met verve. De keuze om gedurende haar eerste huwelijksjaren haar tijd aan huis en haard te besteden en de opvoeding van de kinderen voorrang te geven boven haar eigen intellectuele ontwikkeling en loopbaan wijst op iemand die zich plooit naar omstandigheden en tijd. Ook het wetenschappelijk werk van Hazewinkel-Suringa werd gekenmerkt door balans en synthese. Des te opmerkelijker is het dat zij op politiek gebied veel uitgesprokener was.

Overbeek 1959, p. 7.

Overbeek 1959, p. 8.

Inaugurele rede Amsterdam, De straf en haar achtergrond, Alphen a/d Rijn 1932.

't Hart 2004.

Hazewinkel-Suringa 1996.

L., NJB 1953, p. 660-661.

Hazewinkel-Suringa, bewerkt door J. Remmelink, 1981. 
Leny de Groot-van Leeuwen

\section{Politiek uitgesproken: moedig en sterk ${ }^{29}$}

De universiteit van de vooroorlogse jaren wordt wel beschreven als 'een stille wijkplaats van de geest' die wars was van politiek. ${ }^{30}$ De neutraliteitspolitiek in Nederland creëerde een klimaat waarin gedachten dat het wel meeviel met het nationaalsocialisme en de Duitse dreiging goed konden gedijen. ${ }^{31}$ De rechtenfaculteiten met haar hoogleraren vormden daarop geen uitzondering. 'Slechts weinige juridische hoogleraren hadden zich in de jaren voor 10 mei 1940 tegen het oprukkende nationaalsocialisme gekeerd. Hoewel menigeen lid was van een politieke partij of maatschappelijk actief was het innemen van een politiek standpunt voor een wetenschapper taboe. (...) Men was a-politiek uit beginsel', aldus Corjo Jansen. ${ }^{32}$ Zo niet prof. Hazewinkel-Suringa.

Zij legde op 10 juli 1934 samen met zes andere juristen (hoogleraren, advocaten onder wie een lid van de Eerste Kamer en een wethouder van Amsterdam en een oud-vicepresident van de Amsterdamse rechtbank) een verklaring af over een strafzaak die tegen een Nederlander in Duitsland aanhangig was gemaakt. ${ }^{33}$ Deze Nederlander, Henk Spansier, timmerman, vakbondsman en lid van de SDAP, was op 12 augustus 1933 uit de tram van Nijmegen naar Kleef geplukt door nationaalsocialisten. Hij werd verdacht van het verspreiden van het in Nederland uitgegeven weekblad de Freie Presse. De juristen achtten het onaannemelijk dat de door Spansier gepleegde feiten als landverraad voor Duits recht strafbaar zouden zijn en bovendien dat dit recht een Nederlander die in Nederland een aldaar toegelaten en overal elders verkrijgbaar weekblad verspreidt, als landverrader strafbaar zou stellen. Vrijspraak en invrijheidstelling was dan ook hun verwachting. Mocht dit niet zo zijn, dan 'wijken dit recht en die rechtsopvattingen in zóó sterke mate af van wat in Nederland te dien aanzien geldt, en dan dreigt velen anderen Nederlanders, die in het eigen land aan eenige publicatie betreffende Duitschland hebben medegewerkt en die zich te eenige tijd over de Duitsche grens mochten begeven, een zoodanig gevaar, dat alsdan de berechting van den Nederlander Spansier een aangelegenheid is, waarbij de belangen van de Nederlandsche regering en ook die der openbare meening behoort gevestigd te zijn. Het is met het oog op dit laatste, dat vorengenoemden gemeend hebben goed te doen, tot publicatie van hetgeen hun ter zake bekend is over te gaan.' Uiteindelijk vond op 1 augustus 1934 de besloten zitting plaats in Berlijn, waarbij Spansier tot twee jaar celstraf werd veroordeeld. ${ }^{34}$

Twee jaar later, toen nog steeds vrijwel iedereen in Nederland zich met man en macht trachtte aan te passen aan de opkomst van het nationaalsocialisme in Duitsland, werd Hazewinkel-Suringa lid van het Comité van Waakzaamheid, waarin intellectuelen, onder wie Menno ter Braak, ageerden tegen het fascisme en nationaalsocialisme. In 1938 verscheen een mede door haar ondertekend 'adres 
van intellectuelen' aan de minister van Justitie, gericht tegen de nieuwe koers van de regering omtrent uitwijzing van vreemdelingen en onder andere gepubliceerd in het Zaanse volksblad onder de kop: 'Onze kostbaarste traditie: het asylrecht!'35 Protest werd aangetekend tegen het feit dat mensen die te vrezen hadden voor vervolging vanwege politieke vergrijpen of opvattingen zouden worden uitgezet. Uitzetting komt dan neer op uitlevering. Uitlevering is, aldus de opstellers van het adres, strijdig met het Nederlandse rechtsgevoel door de eeuwen heen.

Eveneens in 1938 wordt onder de kop 'Telegram van Amsterdamsche hoogleeraren aan den minister van Justitie' door diverse dagbladen verslag gedaan van het feit dat acht hoogleraren van de juridische faculteit onder wie HazewinkelSuringa 'langs telegrafische weg in naam van de menschelijkheid een dringend beroep [hebben] gedaan op den minister van justitie, om Duitsch-Joodsche kinderen in zeer grooten getal in Nederland toe te laten. ${ }^{36}$ Dit staat in sterk contrast met de Nederlandse praktijk om joodse vluchtelingen in grote aantallen naar Duitsland terug te sturen. Immers, 'een Duits concentratiekamp betekent geen levensgevaar', aldus de Nederlandse minister van Justitie in $1938 .{ }^{37}$

Maart 1942, toen aan de universiteit een aantal hoogleraren werd ontslagen, diende Hazewinkel-Suringa, inmiddels decaan van de faculteit der rechtsgeleerdheid, samen met de hoogleraar anatomie M.W. Woerdeman een motie in die inhield dat de universiteit zou moeten worden gesloten als de ontslagen niet ongedaan zouden worden gemaakt. Deze motie werd met een meerderheid van 41 tegen 23 stemmen verworpen. ${ }^{38}$

In 1943 liet de Sicherheidspolitzei weten dat de Amsterdamse Universiteit de rustigste van allemaal was. De oproep van Suringa c.s. bleef zonder gevolg en de universiteit bleef gedurende de oorlogstijd open. Verklaringen daarvoor worden gevonden in het feit dat hoogleraren in die tijd in tegenstelling tot studenten en medici bijvoorbeeld niet waren georganiseerd. Voor de Amsterdamse Universiteit speelde een, waarschijnlijk apocriefe, brief van de koningin waarin het openhouden van de universiteit gevraagd werd, eveneens een rol. Knegtmans ziet als belangrijkste factor de afhankelijkheid van de overheid van de rijks- en gemeenteuniversiteiten, die zich meegaander opstelden dan de confessionele universiteiten.

Hazewinkel-Suringa werd in 1942 ontslagen en verbannen uit Amsterdam. Daarin heeft haar collega Van Apeldoorn een belangrijke rol gespeeld. Hij drong in een advies omtrent een voorstel tot gedeeltelijke nazificering van de juridische faculteiten in Amsterdam, Leiden en Utrecht aan op haar ontslag en schreef dat haar onderwijs 'een aan de nationaalsocialistische rechtsopvattingen volkomen vijandig karakter had.' Enkele andere hoogleraren werden eveneens ontslagen, zodat van het hooglerarencorps in 1943 niet veel meer over was. ${ }^{39}$

36 O.a. Algemeen Handelsblad 17 november1938; Leeuwarder Nieuwsblad 18 november 1938; Nieuwsblad van het Noorden 17 november 1938; De Graafschap-bode 18 november 1938.

37 Presser 1965, p. 353.

38 De Jong 1972, p. 561; Blaas 2010, p. 86.

39 Blaas 2010, p. 85. 
Leny de Groot-van Leeuwen

Na de bezetting zette Hazekamp-Suringa haar verzet tegen de politieke mainstream door. Het eerste artikel van haar hand na de Tweede Wereldoorlog, in 1946, behelsde een protest tegen de herinvoering van de doodstraf, en tegen het feit dat dit met terugwerkende kracht gebeurde. ${ }^{40}$ Op 22 december 1943 was door de regering in ballingschap in Londen het 'Koninklijk Besluit Buitengewoon Strafrecht' ondertekend, waarin de in 1870 afgeschafte doodstraf opnieuw in het burgerlijk strafrecht was opgenomen. Deze gold met terugwerkende kracht voor oorlogsmisdadigers. Ook nu ging Hazewinkel-Suringa in tegen de toentertijd heersende mening die in het verzet tegen de doodstraf een vergoelijking zag van het landverraad en de gepleegde misdaden. 'Volksbewustzijn is nog geen rechtsbewustzijn', aldus Hazewinkel-Suringa. 'Het is nu geen oorlog meer. De rechtsstaat dient te herleven.' Naar haar overtuiging 'mag de Staat alleen de doodstraf hanteren, als de veiligheid van de gemeenschap naar's rechters oordeel haar uitdrukkelijk vordert en niet als wraakoefening of talionische vergelding. ${ }^{41}$ Onmiddellijke gevolgen had haar pleidooi bepaald niet. In 1952 was het de laatste keer dat de doodstraf in Nederland werd voltrokken, pas in 1983 werd in artikel 114 van de Grondwet bepaald dat de doodstraf naar Nederlands recht niet kan worden opgelegd.

\section{Actor en factor?}

Hazewinkel-Suringa stond in het leven met een grote mate van authenticiteit en bescheidenheid. Min of meer tegen wil en dank oefende zij invloed uit op andere vrouwen; zij was door anderen gemaakt tot een rolmodel, een factor in de samenleving.

Haar magnum opus over het strafrecht is veelgeprezen en heeft onmiskenbaar invloed gehad op generaties van juristen. Zij was een van de eersten die het recht niet categoriseert ten behoeve van de praktijkjurist en een inleiding tot het strafrecht schrijft, maar zich richt tot de student die moet leren denken over dat recht en dus een inleiding tot de studie van het recht schrijft. Ook haar minder bekende wetenschappelijk werk vindt na vele jaren nog wetenschappelijke weerklank. ${ }^{42}$ Maar in de overzichten van belangrijke Nederlandse juristen ontbreekt zij. Hoe komt dat? 'Dat mevrouw Hazewinkel is afgevallen, komt doordat zij volgens de strafrechtsmedewerker van het $N J B$ - ondanks haar gezaghebbende Inleiding tot de studie van het Nederlandse strafrecht - voor de geschiedenis van de Nederlandse strafrechtsbeoefening in de laatste eeuw minder gezichtsbepalend is geweest dan een aantal andere juristen', aldus de verantwoording van de gemaakte keuzes in

Hazewinkel-Suringa 1946, p. 23.

Zoals blijkt uit het volgende citaat: 'Al in 1959 schreef HS dat "het [beroepsgeheim] wordt beroerd door en [zich] heeft aan te passen aan de evoluerende samenleving met haar telkens nieuwe omstandigheden en intermenselijke verhoudingen (...) het tempora mutantur doet zich volgens haar vooral gelden in de arts-patiënt relatie, 'voeger een intieme relatie tussen en de kranke. Daarom zo besluit zij is het belangrijk dat het beroepsgeheim telkens ter discussie wordt gesteld'. (Buijsen 2012). 
Zestig juristen, Bijdragen tot een beeld van de geschiedenis der Nederlandse rechtswetenschap. ${ }^{43}$ Zo bleef dit overzicht beperkt tot mannelijke juristen.

Voor de oorlog pleitte Hazewinkel-Suringa voor verruiming van het asielrecht, in de oorlog pleitte zij voor het sluiten van de universiteit en na de oorlog hield zij een pleidooi tegen de doodstraf. Iedere keer tevergeefs. De verruiming van het asielrecht kwam er niet, de universiteit bleef open en de doodstraf had nog lange tijd wel een plaats in het recht. Gesteld zou kunnen worden dat HazewinkelSuringa weliswaar een actor was, maar in deze kwesties nimmer de doorslag heeft gegeven. Juist op het terrein waar zij zelf het meest uitgesproken was en een actor van belang wilde zijn, was zij geen juridisch-politieke factor. Gesteld zou echter ook kunnen worden dat moreel hoogstaand gedrag nooit verloren gaat, zelfs als het doel niet bereikt wordt. Net zoals geldt voor degenen die deelnamen aan de Februaristaking in 1941, geldt ook dat haar stem te midden van de morele malaise uit die tijd een houvast bood.

\section{Literatuur}

Blaas, P.M., Henk Hoetink (1900-1963): een intellectuele biografie: recht en geschiedenis, Hilversum: Verloren 2010.

Bosch, M., Het geslacht van de wetenschap. Vrouwen en hoger onderwijs in Nederland 1878-1948, Amsterdam: SUA 1994.

Brauer, J.L.M., 'De zaak Spansier 1933-1935, Nijmeegse vakbondsman voor de nazi-rechters', in: Jaarboek Numaga 2007, 54, p. 128-149.

Buijsen, C.S., Medisch beroepsgeheim in dubio, Rotterdam: Erasmus Universiteit 2012.

CBS, Jaarboek onderwijs in cijfers, 2011.

Drabbe, L.W.M.M., 'De vrouw in de rechterlijke macht', Rechtsgeleerd magazijn Themis 1963, p. 532-548.

Enschedé, Ch.J., 'Prof.mr. D. Hazewinkel-Suringa herdacht', Tijdschrift voor Strafrecht 1970, 79, p. 181-184.

Fischer, A., 'De last van de vrouwelijke emotionaliteit', in: B. van Balen \& A. Fischer, De universiteit als modern mannenklooster, Amsterdam: Het Spinhuis 1998, p. 21-32.

Hagendijk, R., Het studentenleven. Opkomst en verval van de traditionele studentencultuur, Amsterdam: SUA 1980.

Hart, A.C. 't, 'Levensbericht J. Remmelink', in: Levensberichten en herdenkingen, Amsterdam: Royal Netherlands Academy of Arts and Schiences (KNAW) 2004.

Hazewinkel-Suringa, D., Mancipatio en Traditio. Bijdrage tot de kennis van de eigendomsoverdracht in het Romeinse recht, Alphen aan de Rijn: Samsom 1931.

Hazewinkel-Suringa, D., De straf en haar achtergrond (inaugurele rede Universiteit van Amsterdam), Alphen aan de Rijn: Samsom 1932.

Hazewinkel-Suringa, D., 'De Doodstraf, Tijdschrift voor strafrecht 1946, p. 2-23.

Hazewinkel-Suringa, D., Inleiding tot de studie van het Nederlandse strafrecht, Haarlem: H.D. Tjeenk Willink, 1e dr. 1953, 2e dr. 1956; 5e druk bewerkt door J. Remmelink, Haarlem: H.D. Tjeenk Willink 1971; idem 14e druk 1995.

Hazewinkel-Suringa, D., 'De harmonische generatie en de heroïsche groep die daaraan vooraf ging', in: M. Rood-de Boer (red.), Aletta en later, Arnhem: Van Loghum Slaterus 1968, p. 67-88. 
Leny de Groot-van Leeuwen

Hazewinkel-Suringa, D., De doolhof van het beroepsgeheim, Haarlem: H.D. Tjeenk Willink 1959.

Heymans, G., Psychologie der vrouwen, Amsterdam: Wereldbibliotheek 1910.

Jansen, C., 'De zes Nederlandse juridische faculteiten en haar hoogleraren in de Tweede Wereldoorlog', Nederlands Juristen Blad 2005/37, p. 1937-1943.

Jong, L. de, Het Koninkrijk der Nederlanden in de Tweede Wereldoorlog, deel VI, Rijksinstituut voor Oorlogsdocumentatie, Amsterdam/'s-Gravenhage: Nijhoff 1972.

Kloek, E., 1001 vrouwen uit de Nederlandse geschiedenis, Amsterdam/Nijmegen: Uitgeverij Vantilt 2013.

Knegtmans, P. J., Professoren van de stad. Het Athenaem Illustre en de Universiteit van Amsterdam 1632-1960, Amsterdam: Amsterdam University Press 2007.

Knegtmans, P.J., Een kwetsbaar centrum van de geest. De Universiteit van Amsterdam tussen 1935 en 1950, Amsterdam: Amsterdam University Press 1998.

Mok, L., Van codificatie tot codificatie. Een alternatieve blik op 50 jaar rechtsontwikkeling (afscheidscollege als hoogleraar verzekeringsrecht), Deventer: Kluwer 1989.

Nève, P.L., 'Suringa, Derkje (1889-1979)' , in: Bibliografisch Woordenboek van Nederland.

Noordenbos, G., 'Seksestrijd om de ivoren toren. Verklaringen voor de marginale positie van vrouwen aan de universiteit', in: B. van Balen \& A. Fischer, De universiteit als mannenklooster, Amsterdam: Het Spinhuis 1998, p. 75-93.

Overbeek, W.H., 'Professor Hazewinkel en haar studenten', in: Rechtsbinding en Rechtsvinding. Opstellen aangeboden aan prof. dr. D. Hazewinkel-Suringa bij haar aftreden als hoogleraar, Leiden: E.J. Brill 1959, p. 6-9.

Presser, J., Ondergang. De vervolging en verdelging van het Nederlandse Jodendom, deel II, 's-Gravenhage: Staatsuitgeverij 1965.

Remmelink, J., D. Hazewinkel-Suringa's Inleiding tot de studie van het strafrecht, Deventer: Gouda Quint 1996.

Roos, N.H.M. de, Juristerij in Nederland. Sociale ontwikkelingen in de opleiding en de beroepen van juristen, Deventer: Kluwer 1981.

Schuyt, C.J.M., Recht en samenleving, Assen: Van Gorcum 1981.

Veen, T.J. \& P.C. Klop (red.), Zestig juristen. Bijdragen tot een beeld van de geschiedenis der Nederlandse rechtswetenschap, Zwolle: W.E.J. Tjeenk Willink 1987. 